\title{
Thiirane functional spherosilicate as epoxy resin modifier
}

\author{
Synthesis and thermal stability
}

\author{
M. Dutkiewicz $\cdot$ M. Szołyga $\cdot$ H. Maciejewski $\cdot$ \\ B. Marciniec
}

Received: 31 July 2013 / Accepted: 23 February 2014/Published online: 19 March 2014

(C) The Author(s) 2014. This article is published with open access at Springerlink.com

\begin{abstract}
Epoxy resin-based composites, also those containing POSS compounds, have been the subject of extensive research because of their attractive properties and broad practical applications. However, in some applications they suffer from too long curing times or not strong enough adhesion to metals. A solution to this problem is the use of episulfide (thiirane) derivatives or their combination with epoxies. In this paper, the synthesis of new octakis[(3(thiiran-2-yloxy)propyl)dimethylsiloxy]octasilesquioxane from its 3-glycidoxypropyldimethylsiloxy analog is described. Results of study of its influence on thermal properties as well as curing processes of modified with this compound epoxy resins hardened with maleic, phthalic, and pyromellitic anhydrides are also presented. It is shown that addition of this new thiirane functional POSS compound can significantly increase thermal stability of obtained epoxy resin composites and decrease its curing temperatures.
\end{abstract}

Keywords Thiirane Silsesquioxane Epoxide resin $\cdot$ Anhydride

M. Dutkiewicz · B. Marciniec

Advanced Technologies Centre, Adam Mickiewicz University of Poznan, Grunwaldzka 6, 60-780 Poznan, Poland

M. Dutkiewicz · H. Maciejewski

Poznan Science and Technology Park, Adam Mickiewicz

University Foundation, Rubiez 46, 61-612 Poznan, Poland

M. Szołyga · H. Maciejewski · B. Marciniec $(\bowtie)$

Faculty of Chemistry, Adam Mickiewicz University of Poznan,

Umultowska 89b, 61-614 Poznan, Poland

e-mail: marcinb@amu.edu.pl

\section{Introduction}

Polyhedral oligomeric silsesquioxanes (POSS), especially well defined $\mathrm{T}^{8}$ derivatives and spherosilicates which are specific class of POSS, have nowadays become one of the most extensively explored as modifiers and nanobuilding blocks group of compounds. Their popularity and multifarious applications stem from their useful physicochemical properties, ease of chemical modification, reactivity, and nanometric-size [1-14]. From the point of view of chemical synthesis, particularly important are those with reactive functional groups e.g., hydrogen atoms, vinyl, amino, methacryloxy, or chloralkyl ones. Besides the above mentioned, also very important and broadly explored are epoxy-functional silsesquioxanes and spherosilicates. They can be used as starting material for further transformations and synthesis of new compounds [15] as well as components of epoxy nanocomposites influencing and determining their unique parameters like crystallinity, structure, curing temperatures, mechanical, and thermomechanical properties [16-20].

Epoxy resins have been subjects of extensive research, because of their broad practical applications and attractive properties [16-24]. However, in some applications they suffer from too long curing times or not strong enough adhesion to metals. A solution to this problem is the use of episulfide (thiirane) resins or their combination with epoxides. Episulfides should be suitable for low-temperature rapid curing and can react not only with epoxy resin but also with many kinds of metals, because of the formation of thiol (-SH) groups able to form sulfur-metal bonds resulting in improved adhesion and corrosion resistance [21, 25].

Several methods of thiirane synthesis have been proposed in the literature, the majority of them are based on conversion of oxiranes to thiiranes [22, 25-29]. 
As a natural continuation of our earlier work on synthesis of functional POSS compounds exploiting octakis[(3-glycidoxypropyl)dimethylsiloxy]octasilsesquioxane as substrate, we decided to prepare its thiirane analog and use it as a modifier of anhydride cured epoxy resin systems of improved thermal stability. To our best knowledge, this compound has not yet been described in the literature.

\section{Experimental}

All chemicals were used as received from suppliers (Sigma-Aldrich, Gelest, Organika Sażyna S.A.) without any further purification. Water used in the experiments was redistilled freshly before use. Octakis(hydridodimethylsiloxy)octasilsesquioxane was synthesised according to the procedure described elsewhere [30].

Synthesis of octakis[(3-glycidoxypropyl)dimethylsiloxy] octasilsesquioxane (1)

Octakis(hydridodimethylsiloxy)octasilsesquioxane (20 g, $19.6 \mathrm{mmol}$ ) with $20 \%$ excess of allyl-glycidyl ether $(22.4 \mathrm{~mL}, 188 \mathrm{mmol})$ together with $200 \mathrm{~mL}$ of toluene as solvent was placed in a three-necked round bottom flask equipped with a thermometer, a condenser and a magnetic bar. Then Karstedt catalyst $\left(85.6 \mathrm{mg}, 2.35 \times 10^{-6} \mathrm{~mol} \mathrm{Pt}\right)$ was added at room temperature and the solution was heated to $110{ }^{\circ} \mathrm{C}$ and kept at this temperature for $8 \mathrm{~h}$. After the reaction mixture cooled down, the solvent and the excess of olefin were evaporated under vacuum and the residue was filtered off to give a product as an viscous oil (36.8 g, $97 \%$ of theoretical yield). The results of spectroscopic analysis of the product confirmed its structure.

${ }^{1} \mathrm{H}$ NMR $\left(\mathrm{CDCl}_{3}, 298 \mathrm{~K}, 300 \mathrm{MHz}\right) \delta=0.05$ (OS$\left.\mathrm{iCH}_{3}\right) ; 0.51\left(\mathrm{SiCH}_{2}\right) ; 1.51\left(\mathrm{CH}_{2}\right) ; 2.47,2.65\left(\mathrm{CH}_{2} \mathrm{O}\right)$; $3.00(\mathrm{CHO}) ; 3.25\left(\mathrm{CH}_{2} \mathrm{O}\right) ; 3.33,3.56\left(\mathrm{OCH}_{2}\right) \mathrm{ppm}$.

${ }^{13} \mathrm{C} \quad \mathrm{NMR}\left(\mathrm{CDCl}_{3}, 298 \mathrm{~K}, \quad 75.5 \mathrm{MHz}\right) \quad \delta=-0.66$ $\left(\mathrm{SiCH}_{3}\right) ; 13.39\left(\mathrm{SiCH}_{2}\right) ; 22.89\left(\mathrm{CH}_{2}\right) ; 43.98\left(\mathrm{CH}_{2} \mathrm{O}\right)$; $50.29(\mathrm{CHO}) ; 71.75\left(\mathrm{OCH}_{2}\right) ; 73.61\left(\mathrm{CH}_{2} \mathrm{O}\right) \mathrm{ppm}$.

${ }^{29} \mathrm{Si} \quad \mathrm{NMR}\left(\mathrm{CDCl}_{3}, \quad 298 \mathrm{~K}, \quad 59,6 \mathrm{MHz}\right) \quad \delta=12.87$ $\left(\mathrm{OSi}\left(\mathrm{CH}_{3}\right)_{2}\right) ;-109.13$ (SiOSi) ppm.

FT-IR (ATR): 2998, 2955, 2931, 2869, 1253, 1070, 902, $838,547 \mathrm{~cm}^{-1}$.

Synthesis of octakis[(3-(thiiran-2-

yloxy)propyl)dimethylsiloxy]octasilsesquioxane (2)

A general procedure for the synthesis of octakis[(3-(thiiran-2yloxy)propyl)dimethylsiloxy]octasilsesquioxane was similar to that described by Cheng and co-workers (applied for the synthesis of different compounds [25]) with slight modifications.

In a three-necked round bottom flask, quipped with a thermometer, condenser, magnetic stirrer, and an addition funnel $16 \mathrm{~g}(164.8 \mathrm{mmol})$ of potassium thiocyanate was dissolved in $24 \mathrm{~mL}$ of distilled water. The additional funnel was filled up with a solution of $20 \mathrm{~g}(10.4 \mathrm{mmol})$ of octakis[(3-glycidoxypropyl)dimethylsiloxy] octasilsesquioxane in $120 \mathrm{~mL}$ of 2-propanol. Then, the solution of epoxy spherosilicate solution was slowly added dropwise to the thiocyanate solution on vigorous stirring. The reaction mixture was heated up to $60{ }^{\circ} \mathrm{C}$ and kept at this temperature for $24 \mathrm{~h}$. After cooling down, the solution was transferred to the separation funnel and $120 \mathrm{~mL}$ of methylene chloride was added. The organic phase was collected, washed with distilled water three times and dried over anhydrous sodium sulfate. The product was isolated by vacuum evaporation of the solvent and characterized with NMR and FT-IR spectroscopies.

${ }^{1} \mathrm{H} \mathrm{NMR}\left(\mathrm{CDCl}_{3}, 298 \mathrm{~K}, 300 \mathrm{MHz}\right) \delta=0.14\left(\mathrm{SiCH}_{3}\right)$;
$0.47\left(\mathrm{SiCH}_{2}\right) ; 1.51\left(\mathrm{CH}_{2}\right) ; 2.18\left(\mathrm{SCH}_{2}\right) ; 2.97(\mathrm{SCH}) ;$
$3.38\left(\mathrm{H}_{2} \mathrm{CO}\right) ; 3.55,388\left(\mathrm{OCH}_{2}\right) \mathrm{ppm}$.
${ }^{13} \mathrm{C} \mathrm{NMR}\left(\mathrm{CDCl}_{3}, 298 \mathrm{~K}, 75.5 \mathrm{MHz}\right) \delta=-0.30$
$\left(\mathrm{SiCH}_{3}\right) ; 13.83\left(\mathrm{SiCH}_{2}\right) ; 23.19\left(\mathrm{CH}_{2}\right) ;$
$24.89\left(\mathrm{SCH}_{2}\right) ; 31.71 \quad(\mathrm{SCH}) ; 73.92\left(\mathrm{H}_{2} \mathrm{CO}\right) ; 79.90$
$\left(\mathrm{OCH}_{2}\right) \mathrm{ppm}$.
${ }^{29} \mathrm{Si} \mathrm{NMR}\left(\mathrm{CDCl}_{3}, 298 \mathrm{~K}, \quad 59.6 \mathrm{MHz}\right) \delta=15.73$
$\left(\mathrm{OSi}(\mathrm{CH} 3)_{2}\right) ;-109.04(\mathrm{SiOSi}) \mathrm{ppm}$.
$\mathrm{FT}-\mathrm{IR}(\mathrm{ATR}): 2957,2928,2859,1257,1074,800,729$,
$617 \mathrm{~cm}^{-1}$

Curing procedure

All cured samples were prepared in the same way and cured in the same conditions. To a portion of Epidian 6 (E6) epoxy resin of the epoxide index in the range from 0.51 to 0.54 , a portion of octakis[(3-glycidoxypropyl)dimethylsiloxy]octasilsesquioxane (POSS-O) or octakis[(3-(thiiran-2-yloxy)propyl)dimethylsiloxy]octasilsesquioxane (POSS-S) making 10 mass $\%$ of the epoxide resin was added at room temperature and was stirred together for several minutes. Then, the appropriate amount of phthalic (PHT), maleic (MAL), or pyromellitic (PYR) anhydride was added to the mixture, and the contents were stirred again. The samples prepared were then cured for $1 \mathrm{~h}$ at $200{ }^{\circ} \mathrm{C}$ and left for $24 \mathrm{~h}$ at room temperature. The amounts of hardener (anhydride) were chosen to ensure the anhydride to oxirane and/or thiirane groups ratio of 0.5 . According to the procedure described, three sets of samples were prepared differing in the type of curing agent and modifier used. The amounts of substrates used are listed in Table 1 . The cured samples were subjected to TG analysis. 
Table 1 The amounts of substrates used for samples preparation

\begin{tabular}{lllllll}
\hline Sample & \multicolumn{7}{l}{ Substrate amounts/g } \\
\cline { 2 - 7 } & E6 & POSS-O & POSS-S & PYR & PHT & MAL \\
\hline E6/PYR & 5 & - & - & 1.4 & - & - \\
E6/PYR/POSS-O & 5 & 0.5 & - & 1.5 & - & - \\
E6/PYR/POSS-S & 5 & - & 0.5 & 1.5 & - & - \\
E6/PHT & 5 & - & - & - & 1.9 & - \\
E6/PHT/POSS-O & 5 & 0.5 & - & - & 2.0 & - \\
E6/PHT/POSS-S & 5 & - & 0.5 & - & 2.0 & - \\
E6/MAL & 5 & - & - & - & - & 1.3 \\
E6/MAL/POSS-O & 5 & 0.5 & - & - & - & 1.4 \\
E6/MAL/POSS-S & 5 & - & 0.5 & - & - & 1.4 \\
\hline
\end{tabular}

${ }^{1} \mathrm{H}$ NMR $(300 \mathrm{MHz}),{ }^{13} \mathrm{C}$ NMR $(75 \mathrm{MHz})$, and ${ }^{29} \mathrm{Si}$ MNR (59 MHz) spectra were recorded on a Varian XL 300 spectrometer at room temperature using $\mathrm{CDCl}_{3}$ as solvent. FT-IR spectra were recorded on a Bruker Tensor 27 Fourier Transform spectrometer equipped with a SPECAC Golden Gate diamond ATR unit. For all spectra, 16 scans at a resolution of $2 \mathrm{~cm}^{-1}$ were collected. Thermal stabilities of the samples prepared were measured on a Q50-TGA thermogravimetric analyzer (TA Instruments, Inc.) under nitrogen at flow rate of $60 \mathrm{~mL} \mathrm{~min}^{-1}$. Samples $(10-15 \mathrm{mg}$ ) loaded in a platinum pan were heated from RT to $800{ }^{\circ} \mathrm{C}$ at a rate of $20{ }^{\circ} \mathrm{C} \mathrm{min}{ }^{-1}$. DSC measurements for the determination of curing profiles were carried out on a differential scanning calorimeter DSC-1 (Mettler-Toledo) under air atmosphere at a heating rate of $10{ }^{\circ} \mathrm{C} \mathrm{min}^{-1}$. Samples for DSC experiment of about $20 \mathrm{mg}$ were prepared according to the curing procedure given above (see Table 1) and placed in $40-\mu \mathrm{L}$ aluminum pans with a pierced lid and subjected to the analysis immediately after preparation.

\section{Results and discussion}

The above-described methodology of thiirane-POSS derivative synthesis, starting from the appropriate epoxy-
POSS derivative seems to be optimal (Fig. 1). The use of $\mathrm{KSCN}$ as a sulfur donor permitted obtaining the target compound in high yield. Attempts at replacement of potassium thiocyanate with thiourea without changing any other reaction parameter resulted in a significant decrease in the final product yield (from 70 to $45 \%$ ).

The FT-IR product spectra reveal significant changes in the range from 500 to $1,000 \mathrm{~cm}^{-1}$ (Fig. 2). The bands at 547, 839, and $902 \mathrm{~cm}^{-1}$ present in the substrate spectrum and coming from oxirane ring disappear, while new bands appear at $617,694,729$, and $800 \mathrm{~cm}^{-1}$, and according to the literature, they can be assigned to thiirane group [31-33].

Analysis of TG curves (Fig. 3) confirmed the influence of either of the two additives (POSS-O and POSS-S) on thermal properties of epoxy resins. The effect of the additives was described in terms of the temperatures of 1 , 5 , and $10 \%$ mass loss and $\Delta T$ values for each sample series were calculated. All data obtained are presented in Table 2 .

The influence of octakis[(3-(thiiran-2-yloxy)propyl)dimethylsiloxy] octasilsesquioxane (POSS-S) addition on the thermal properties of epoxy resin is more pronounced than that of its oxirane analog. It is especially noticeable for Epidian 6 samples hardened with maleic anhydride. The difference between the temperature of $1 \%$ mass loss of the sample without any modifier and the sample containing $10 \%$ of POSS-S is higher than $100{ }^{\circ} \mathrm{C}$. For the temperatures of 5 and $10 \%$ mass loss, the difference in $\Delta T$ is not as high, but still exceeds 50 or $60{ }^{\circ} \mathrm{C}$. The differences in thermal stability of Epidian 6 cured with pyromellitic anhydride modified with either of the two spherosilicates are not so remarkable but still considerable. Unfortunately, it is not possible to analyze the influence of additives used on the thermal stability of the system cured with phthalic anhydride, because only the sample modified with thiirane derivative was hardened. However, this result confirms higher reactivity of thiirane groups than that of oxirane ones. Analysis of TG curves also indicated a higher ash residue in the samples containing silsesquioxane.

Performed DSC measurements also revealed influence of POSS additives on epoxy resin properties - their curing

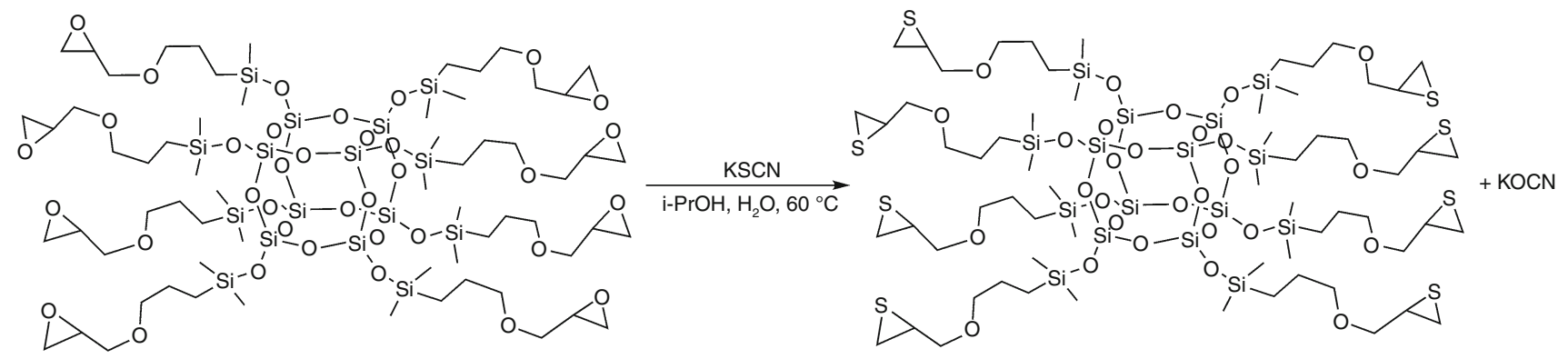

Fig. 1 Synthesis of octakis[(3-(thiiran-2-yloxy)propyl)dimethylsiloxy]octasilsesquioxane 


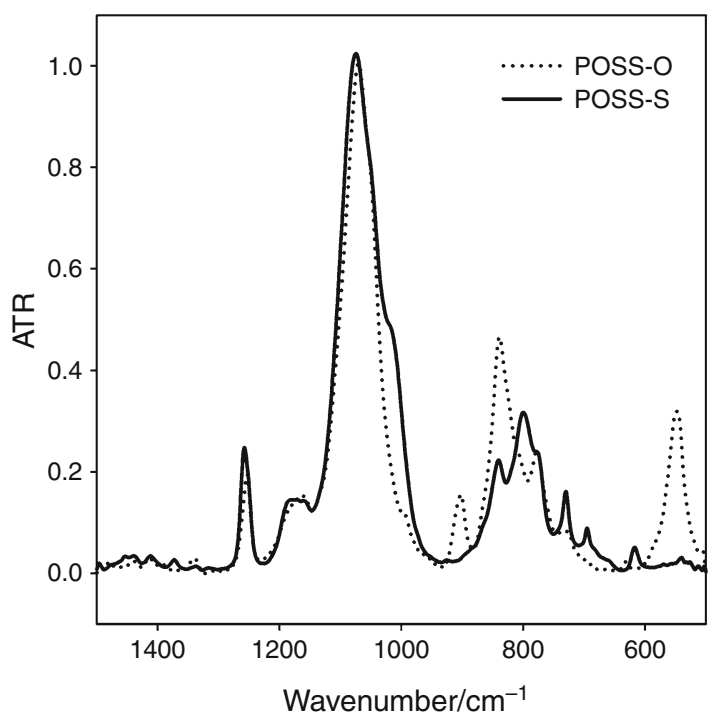

Fig. 2 FT-IR spectra of substrate (POSS-O) and product (POSS-S)
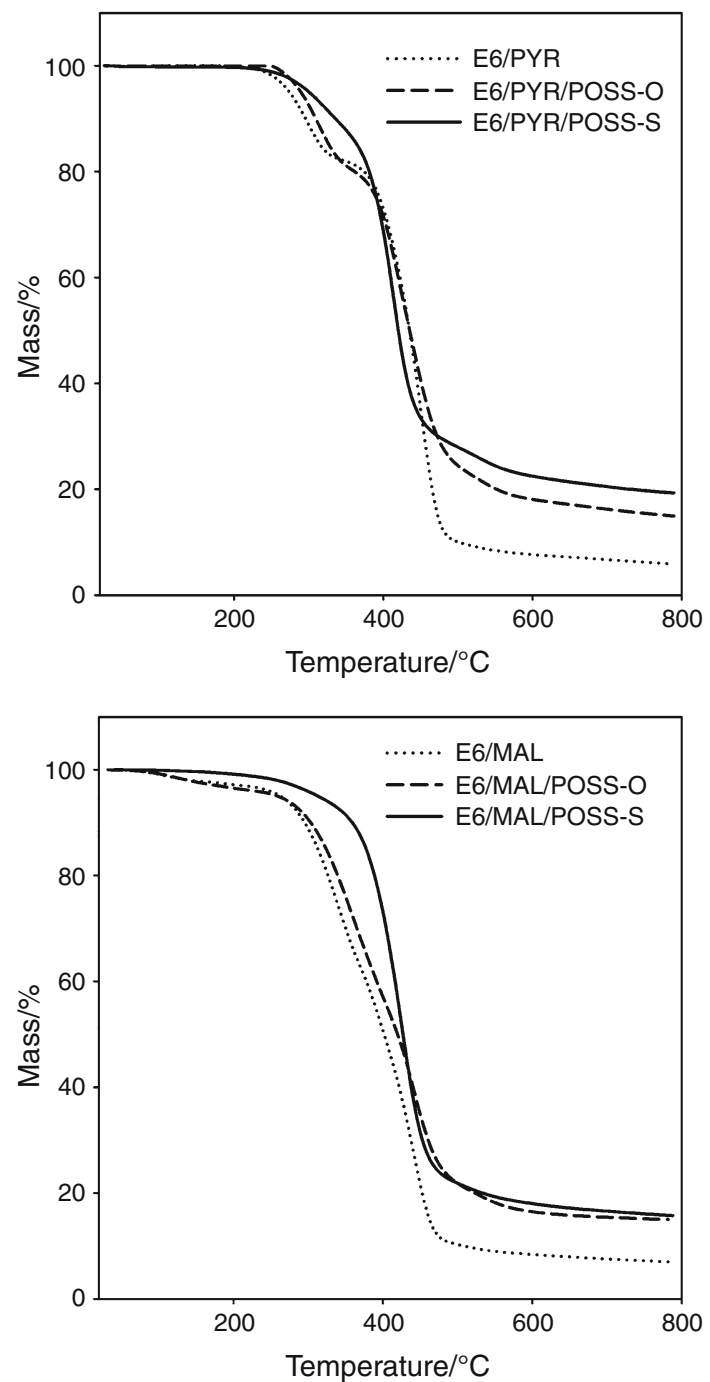

Fig. 3 TG curves of POSS modified Epidian 6 hardened with maleic and pyromellitic anhydrides
Table 2 Mass loss temperatures for all samples read of TG curves

\begin{tabular}{|c|c|c|c|c|c|c|}
\hline \multirow[t]{2}{*}{ Sample } & \multicolumn{6}{|c|}{ Mass loss temperature $/{ }^{\circ} \mathrm{C}$} \\
\hline & $1 \%$ & $\Delta T$ & $5 \%$ & $\Delta T$ & $10 \%$ & $\Delta T$ \\
\hline E6/PYR ${ }^{\mathrm{a}}$ & 238.5 & - & 274.5 & - & 295.9 & - \\
\hline E6/PYR/POSS-O & 263.2 & 24.7 & 289.8 & 15.3 & 309.5 & 13.6 \\
\hline E6/PYR/POSS-S & 246.6 & 8.1 & 300.8 & 26.3 & 336.1 & 40.2 \\
\hline $\mathrm{E} 6 / \mathrm{PHT}^{\mathrm{b}}$ & - & - & - & - & - & - \\
\hline E6/PHT/POSS-O ${ }^{\mathrm{b}}$ & - & - & - & - & - & - \\
\hline E6/PHT/POSS-S & 129.8 & - & 218.1 & - & 229 & - \\
\hline E6/MAL ${ }^{a}$ & 104.5 & - & 263.2 & - & 295.6 & - \\
\hline E6/MAL/POSS-O & 108.7 & 4.2 & 259.6 & -3.6 & 303.7 & 8.1 \\
\hline E6/MAL/POSS-S & 212.5 & 108 & 313.5 & 50.3 & 359.3 & 63.7 \\
\hline
\end{tabular}

Table 3 Results of DSC measurements

\begin{tabular}{llll}
\hline Sample & Peak temperature $/{ }^{\circ} \mathrm{C}$ & Peak width ${ }^{\circ} \mathrm{C}$ & $\begin{array}{l}\Delta H / \\
\mathrm{J} \mathrm{g}^{-1}\end{array}$ \\
\hline E6/PYR & 191.2 & 39.2 & 201.7 \\
E6/PYR/POSS-O & 189.4 & 51.6 & 175.5 \\
E6/PYR/POSS-S & 128.0 & 36.9 & 117.2 \\
E6/PHT & - & - & - \\
E6/PHT/POSS-O & 210.9 & 50.8 & 11.6 \\
E6/PHT/POSS-S & 257.9 & 48.3 & 167.2 \\
E6/MAL & 265.8 & 64.0 & 38.6 \\
E6/MAL/POSS-O & 245.9 & 87.1 & 58.9 \\
E6/MAL/POSS-S & 122.7 & 27.6 & 50.5 \\
\hline
\end{tabular}

processes in this case. It is especially significant for octakis [(3-(thiiran-2-yloxy)propyl)dimethylsiloxy]octasilsesquioxane modified compositions regardless of the hardener used (see Table 3).

For all samples prepared with thiirane additive, curing peak was narrower than for samples prepared with epoxy POSS or without any modifier. It is also important that peak temperatures of curing processes were significantly decreased for samples hardened with pyromellitic and maleic anhydrides and containing thiirane or epoxy POSS additives. The type of additive also influences the enthalpy of curing process. For samples hardened with pyromellitic anhydride, enthalpy decreases from $201.7 \mathrm{~J} \mathrm{~g}^{-1}$ for sample without any POSS additive to $175.5 \mathrm{~J} \mathrm{~g}^{-1}$ for sa mple modified with 10 mass\% of epoxy POSS derivative and down to $117.2 \mathrm{~J} \mathrm{~g}^{-1}$ for sample modified with 10 mass $\%$ of thiirane compound. Also, there is a significant change of curing enthalpy of epoxy resin in the presence of phthalic anhydride. No reaction was observed in this case for sample containing no additive, curing enthalpy of sample 

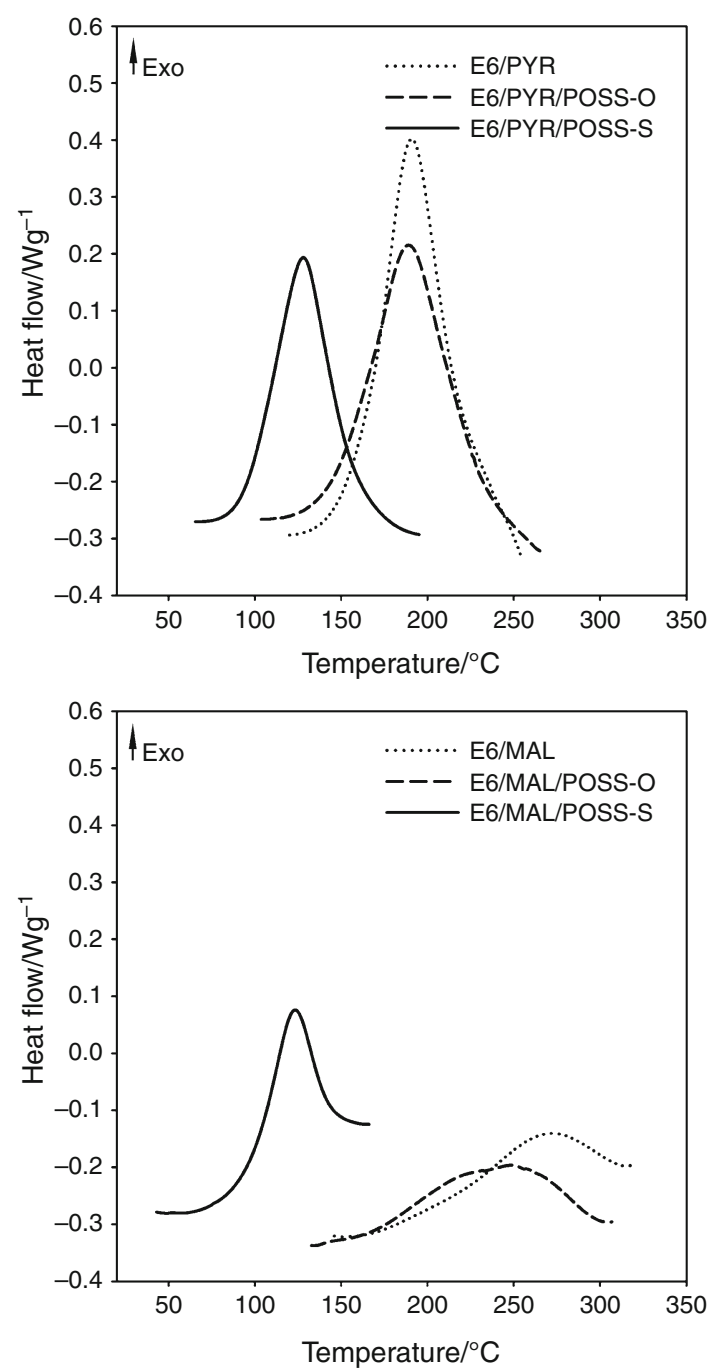

Fig. 4 DSC curing profiles of POSS modified Epidian 6 hardened with maleic and pyromellitic anhydrides

modified with epoxy POSS derivative was relatively low $\left(11.6 \mathrm{~J} \mathrm{~g}^{-1}\right.$ ) and raised up to $167.2 \mathrm{~J} \mathrm{~g}^{-1}$ for sample containing 10 mass\% of octakis[(3-(thiiran-2-yloxy)propyl)dimethylsiloxy] octasilsesquioxane. Those results are in good compliance with macroscopic observations and fact that only last sample from this series was hardened under applied curing procedure. Curves of curing recorded for samples hardened with maleic and pyromellitic anhydrides are shown on below figure (Fig. 4).

\section{Conclusions}

Exploring the known reaction mechanism, a new, not reported up to date octakis[(3-(thiiran-2-yloxy)propyl)dimethylsiloxy]octasilsesquioxane was synthesized in good yield and applied as epoxy resin modifier, enhancing its thermal stability and influencing the curing process. The materials obtained exhibited temperatures of $1 \%$ mass loss even by $100{ }^{\circ} \mathrm{C}$ higher than that of raw materials. Improved thermal stability of epoxies modified with octakis[(3-(thiiran-2-yloxy)propyl)dimethylsiloxy] octasilsesquioxane can be attributed to the possibility of formation of sulfur-containing bridges, additionally crosslinking the polymer. Obtained DSC experiment results have shown that application of octakis[(3-(thiiran-2-yloxy)propyl)dimethylsiloxy]octasilsesquioxane as modifier in described compositions can cause significant decrease of curing temperature and narrowing of curing temperature range.

Acknowledgements The authors gratefully acknowledge the financial support from the European Regional Development Fund, Operational Programme Innovative Economy, 2007-2013, Project No. UDA-POIG.01.03.01-30-173/09.

Open Access This article is distributed under the terms of the Creative Commons Attribution License which permits any use, distribution, and reproduction in any medium, provided the original author(s) and the source are credited.

\section{References}

1. Baney RH, Itoh M, Sakakibara A, Suzuki T. Silsesquioxanes. Chem Rev. 1995;95:1409-30.

2. Gnanasekaran D, Madhavan K, Reddy BSR. Developments of polyhedral oligomeric silsesquioxanes (POSS), POSS nanocomposites and their applications: a review. J Sci Ind Res. 2009:68:437-64.

3. Cordes DB, Lickiss PD, Rataboul F. Recent developments in the chemistry of cubic polyhedral oligosilsesquioxanes. Chem Rev. 2010;110:2081-173.

4. Choi J, Kim S, Laine R. Organic/inorganic hybrid epoxy nanocomposites from aminophenylsilsesquioxanes. Macromolecules. 2004;37:99-109.

5. Lin H, Wu S, Huang P, Huang C, Kuo S, Chang S. Polyhedral oligomeric silsesquioxane containing copolymers for negativetype photoresists. Macromol Rapid Commun. 2006;27:1550-5.

6. Yu J, Qiu Z. Preparation and properties of biodegradable poly(1lactide)/octamethyl-polyhedral oligomeric silsesquioxanes nanocomposites with enhanced crystallization rate via simple melt compounding. ACS Appl Mater Interfaces. 2011;3:890-7.

7. Wang X, Ervithayasuporn V, Zhang Y, Kawakami Y. Reversible self-assembly of dendrimer based on polyhedral oligomeric silsesquioxanes (POSS). Chem Commun. 2011;47:1282-4.

8. Tanaka K, Inafuku K, Nakab K, Chujo Y. Enhancement of entrapping ability of dendrimers by a cubic silsesquioxane core. Org Biomol Chem. 2008;6:3899-901.

9. Fabritz S, Hörner S, Könning D, Empting M, Reinwarth M, Dietz C, Glotzbach B, Frauendorf H, Kolmar H, Avrutina O. From pico to nano: biofunctionalization of cube-octameric silsesquioxanes by peptides and miniproteins. Org Biomol Chem. 2012;10:6287-93.

10. Duchateau R. Incompletely condensed silsesquioxanes: versatile tools in developing silica-supported olefin polymerization catalysts. Chem Rev. 2002;102:3525-42.

11. Ventura M, Mosquera MEG, Cuenca T, Royo B, Jimenez G. Cyclopentadienyl-silsesquioxane titanium complexes: highly active catalysts for epoxidation of alkenes with aqueous hydrogen peroxide. Inorg Chem. 2012;51:6345-9. 
12. Cho HJ, Hwang DH, Lee JI, Jung YK, Park JH, Lee J, Lee SK, Shim HK. Electroluminescent polyhedral oligomeric silsesquioxane-based nanoparticle. Chem Mater. 2006;18:3780-7.

13. Ervithayasuporn V, Abe J, Wang X, Matsushima T, Murata H, Kawakami Y. Synthesis, characterization, and OLED application of oligo(p-phenylene ethynylene)s with polyhedral oligomeric silsesquioxanes (POSS) as pendant groups. Tetrahedron. 2010;66:9348-55.

14. Yang XH, Giovenzana T, Feild B, Jabbour GE, Sellinger A. Solution processeable organic-inorganic hybrids based on pyrene functionalized mixed cubic silsesquioxanes as emitters in OLEDs. J Mater Chem. 2012;22:12689-94.

15. Dutkiewicz M, Maciejewski H, Marciniec B. Synthesis of azido-, hydroxy- and nitro-, hydroxy-functionalized spherosilicates via oxirane ring-opening reactions. Synthesis. 2012;44:881-4.

16. Lin P-H, Khare R. Glass transition and structural properties of glycidyloxypropyl-heptaphenyl polyhedral oligomeric silsesquioxane-epoxy nanocomposites. $\mathrm{J}$ Therm Anal Calorim. 2010;102:461-7.

17. Choi J, Harcup J, Yee AF, Zhu Q, Laine RM. Organic/inorganic hybrid composites from cubic silsesquioxanes. J Am Chem Soc. 2001;123:11420-30.

18. Ramírez C, Abad MJ, Barral L, Cano J, Díez FJ, López J, Montes R, Polo J. Thermal behaviour of a polyhedral oligomeric silsesquioxane with epoxy resin cured by diamines. J Therm Anal Calorim. 2003;72:421-9.

19. Liu Y, Zheng S, Nie K. Epoxy nanocomposites with octa(propylglycidyl ether) polyhedral oligomeric silsesquioxane. Polymer. 2005;46:12016-25.

20. Ramírez C, Rico M, Vilarino JML, Barral L, Ladra M, Montero B. Study of an octaepoxysilsesquioxane cured with a diamine. J Therm Anal Calorim. 2005;80:153-7.

21. Tsuchida K, Bell JP. New epoxy/episulfide resin system for electronic applications. I. Curing mechanism and properties. J Appl Polym Sci. 2001;79:1359-70.
22. Bell JP, Don TM, Voong S, Femandez A, Ku W. Synthesis and properties of epoxy-episulfide resins. Angew Makromol Chem. 1996;240:67-81.

23. Luo $\mathrm{X}$, Zheng $\mathrm{S}$, Ma $\mathrm{D}, \mathrm{Hu} \mathrm{K}$. Mechanical relaxation and intermolecular interaction in epoxy resins/poly (ethylene oxide) blends cured with phthalic anhydride. Chin J Polym Sci. 1995;13:144-53.

24. Freeman ES, Becker AJ. Thermal degradation of nadic methyl anhydride-crosslinked novolac epoxy resin. J Polym Sci A. 1968:6:2829-51.

25. Li Y, Cheng J, Zhang J. Study on the synthesis of thiirane. J Appl Polym Sci. 2006;101:4023-7.

26. Tamami B, Borujeny KP. Synthesis of thiiranes from oxiranes using cross-linked polystyrene supported aluminium chloride as a catalyst. Synt Commun. 2004;34:65-70.

27. Das B, Reddy VS, Krishnaiah M. An efficient catalyst-free synthesis of thiiranes from oxiranes using polyethylene glycol as the reaction medium. Tetrahedron Lett. 2006;47:8471-3.

28. Yadav JS, Reddy BVS, Reddy ChS, Rajasekhar K. [Bmim]PF6: a novel and recyclable ionic liquid for conversion of oxiranes to thiiranes in aqueous media. J Org Chem. 2003;68:2525-7.

29. Kaboudin B, Norouzi H. A new, efficient, and simple method for the synthesis of thiiranes from epoxides under solvent-free conditions. Tetrahedron Lett. 2004;45:1283-5.

30. Filho NLD, de Aquino HA, Pires G, Caetano L. Relationship between the dielectric and mechanical properties and the ratio of epoxy resin to hardener of the hybrid thermosetting polymersrmosetting polymers. J Braz Chem Soc. 2006;17:533-41.

31. Aleksanyan VT, Kuz'yants GM. The vibrational spectra of thiirane. J Struct Chem. 1971;12:243-7.

32. Stuart B. Infrared spectroscopy: fundamentals and applications. Chichester: Wiley; 2004.

33. Socrates G. Infrared and Raman characteristic group frequencies tables and charts. Chichester: Wiley; 2001. 